\title{
Endoparasites of European perch Perca fluviatilis fry: role of spatial segregation
}

\author{
Roman Kuchta $^{1, *}$, Martin Čech ${ }^{2}$, Tomáš Scholz ${ }^{1}$, Miroslava Soldánová ${ }^{1}$, \\ Céline Levron ${ }^{1}$, Blanka Škoríková ${ }^{1}$ \\ ${ }^{1}$ Institute of Parasitology and ${ }^{2}$ Institute of Hydrobiology, Biology Centre of the Academy of Sciences of the Czech Republic, \\ České Budějovice, Branišovská 31, 37005 České Budějovice, Czech Republic
}

\begin{abstract}
A total of 246 perch Perca fluviatilis L. fry, 20 to 106 d old from 3 different reservoir subpopulations (epipelagic perch fry, EPF; bathypelagic perch fry, BPF; littoral perch fry, LPF), were examined for parasites. Six species of endoparasites were found: the nematode Camallanus lacustris was the most common, followed by the cestodes Proteocephalus percae, Bothriocephalus claviceps, Glanitaenia osculata and the acanthocephalan Acanthocephalus lucii. All worms were juvenile or immature and were recovered from the intestinal lumen, with the exception of plerocercoids of Triaenophorus nodulosus, which were found in the body cavity or already encysted in the liver (the final site of infection of metacestodes). A marked difference was found in infection rates in the 3 spatially segregated subpopulations of perch fry. Parasites were found almost exclusively in LPF, which were heavily infected (overall prevalence $=30 \%$ ) compared with the other studied subpopulations. Two species (C. lacustris and T. nodulosus) were found in 1 fish each (prevalence $=3 \%$ ) in BPF, whereas EPF were uninfected. The species richness and prevalence of parasites in LPF increased from 20-24 d old fry ( 2 species of parasites; prevalence $=13 \%$ ) to $106 \mathrm{~d}$ old fry (5 species of parasites; prevalence $=80 \%$ ).
\end{abstract}

KEY WORDS: Acanthocephala - Age dynamics - Cestoda $\cdot$ Helminths $\cdot$ Nematoda $\cdot$ Recruitment · Freshwater · Parasite

\section{INTRODUCTION}

European perch Perca fluviatilis L. is a common freshwater fish widely distributed in the Palaearctic Region that hosts a large number of parasites, especially endoparasites, such as trematodes, cestodes and nematodes (Bauer 1987, Carney \& Dick 1999, Wierzbicka et al. 2005). The parasite fauna of perch in Europe is relatively well studied, but little is known about the age dynamics of infections with endoparasites and almost no information exists on parasitism in the early ontogenetic stages (i.e. larvae and early juveniles).
In deep canyon-shaped reservoirs, perch fry occur as 3 different subpopulations: epipelagic, bathypelagic and littoral (Čech et al. 2005). Epipelagic perch fry $(\mathrm{EPF})$ spend all their time in the upper $4 \mathrm{~m}$ of the water column (i.e. above the thermocline). Bathypelagic perch fry (BPF) exhibit regular diurnal vertical migrations staying in dark conditions in deep cold water during daylight hours (Čech \& Kubečka 2006, Čech et al. $2007 a, b)$ and spending the night in relatively warm surface water (Čech et al. 2005). The temperature difference between epipelagic and bathypelagic habitats, the habitats where the EPF and the BPF subpopulations occur, respectively, during daylight hours is usu- 
ally $5-10^{\circ} \mathrm{C}$ (Čech et al. 2005, Čech \& Kubečka 2006). At least part of the littoral perch fry (LPF) subpopulation has diurnal horizontal migrations, and is present in shallow littoral habitat during the daylight and found in the epilimnion during the night (Gliwicz \& Jachner 1992, Vašek et al. 2006). However, most of the LPF subpopulation is present in a warm littoral habitat $24 \mathrm{~h}$ $\mathrm{d}^{-1}$ (Čech et al. 2005). It is unknown whether this unique spatial and behavioural segregation of these 3 perch fry subpopulations is reflected in their recruitment of parasites and parasite richness.

Parasites are useful indicators of the biology of their hosts including diet, migration and population differentiation (Williams et al. 1992, MacKenzie et al. 1995) as well as food-web structure (Marcogliese et al. 2006). On the other hand, parasitism may influence the behaviour of fish (or hosts), which results in differential habitat use and an increase in vulnerability to predators by infected individuals (Seppälä et al. 2005). Here we address questions of whether (1) there are differences in the prevalence of parasites among 3 different subpopulations of perch fry (EPF, BPF, LPF) and (2) parasite prevalence and their numbers increased with the age of fry.

\section{MATERIALS AND METHODS}

The study was carried out in the deep, canyonshaped Římov Reservoir, Czech Republic, $170 \mathrm{~km}$ south of Prague $\left(48^{\circ} 50^{\prime} \mathrm{N}, 14^{\circ} 30^{\prime} \mathrm{E}\right)$ in 2006 to 2008. The reservoir has a surface area of $2.1 \mathrm{~km}^{2}$ and a maximum depth of $45 \mathrm{~m}$. Fish were sampled during mid-day (10:00 to 14:00 h) on 6 sampling dates (see Table 1). The EPF were caught at a depth of 0 to $2 \mathrm{~m}$ below the water surface using the multifunctional RV 'Ota Oliva' and an ichthyoplankton frame trawl $(2 \times$ $2 \mathrm{~m}$ mouth opening, $1 \times 1.35 \mathrm{~mm}$ mesh size). The BPF were caught using the same equipment at a depth of 11 to $13 \mathrm{~m} \mathrm{(2006} \mathrm{and} \mathrm{2008)} \mathrm{and} 7$ to $9 \mathrm{~m}$ (2007) below the water surface, i.e. in all cases well below the thermocline (ca. $4 \mathrm{~m}$ deep). The depth of the BPF subpopulation was continually checked with a split-beam scientific echosounder (either SIMRAD EY 500 or SIMRAD EK 60); the accuracy of the depth of the towed net for sampling the BPF was checked by a commercial echosounder (Eagle Ultra Classic; for details of pelagic sampling see Čech et al. 2005, 2007b). By performing several vertical tows of the net, Čech et al. (2005) verified that contamination of ichthyoplankton catches of the BPF by the EPF when pulling the net from the deeper layers to the surface is negligible. Moreover, the BPF lifted from depths of 7 to 9 or 11 to $13 \mathrm{~m}$ always had overfilled swim bladders and were easily distinguishable from the EPF. Both EPF and BPF were caught at least $100 \mathrm{~m}$ from the shore in an area where both epipelagic and bathypelagic habitats were well developed. The LPF were caught using a shorthandled dip net $(0.5 \mathrm{~m}$ in diameter, $0.2 \times 0.2 \mathrm{~mm}$ mesh size $)$, fry beach seine net $(2 \times 10 \mathrm{~m}$, mesh size $1 \times$ $1.35 \mathrm{~mm}$ ) and later in the season using an electrofishing boat in a shallow littoral area of the reservoir (maximum distance from the shore $=5 \mathrm{~m}$, maximum depth $=$ $1 \mathrm{~m})$.

Perch fry were transported to the laboratory alive in plastic containers and immediately pressed individually between glass plates and screened for parasites with the aid of a high magnification stereomicroscope or light microscope. Parasites were further examined in vitro using an Olympus BX 51 microscope with Nomarski interference contrast (NIC) and identified on the basis of relevant literature (Ergens \& Lom 1970, Kuperman 1973, Scholz 1989, Moravec 1994, Scholz \& Hanzelová 1998). The age of perch fry was estimated using otoliths, i.e. daily increments in the sagittae (Campana 1992). The total length (TL in $\mathrm{mm}$ ) of each fish was measured from the tip of the mouth to the end of the caudal fin with a plastic ruler.

The morphometric data (TL) were analyzed using the software package Statistica 6.0 (1997) (StatSoft). To improve the fit of the normal distribution, a $\log _{10}$ transformation was performed on the prevalence of parasites. Univariate comparisons of parasite species present for each variable were performed separately using 1-way ANOVA. If this test indicated significant differences between the subpopulations, post-hoc Tukey's Honestly Significant Difference (HSD) test with unequal sample sizes was used.

\section{RESULTS}

A total of 246 perch fry from 20 to $106 \mathrm{~d}$ old were examined for parasites (Table 1). The mean, maximum

Table 1. Perca fluviatilis. Age, sampling date (d/mo/yr) and numbers of examined and infected epipelagic (EPF), bathypelagic (BPF) and littoral (LPF) perch fry from the 3 habitats. The number of age-stratified samples containing infected fish is shown in bold text

\begin{tabular}{|lccccc|}
\hline Age $(\mathrm{d})$ & Date & Total & EPF & BPF & LPF \\
\hline 20 & $7 / 6 / 06$ & 30 & 10 & 10 & $10 / \mathbf{3}$ \\
24 & $24 / 5 / 07$ & 60 & 20 & $20 / \mathbf{1}$ & $20 / \mathbf{1}$ \\
24 & $29 / 5 / 08$ & 45 & 15 & $15 / \mathbf{1}$ & $15 / \mathbf{2}$ \\
44 & $13 / 6 / 07$ & 71 & 20 & 20 & $31 / \mathbf{5}$ \\
72 & $11 / 7 / 07$ & 20 & 0 & 0 & $20 / \mathbf{8}$ \\
106 & $14 / 8 / 07$ & 20 & 0 & 0 & $20 / \mathbf{1 6}$ \\
Total & & 246 & 65 & $65 / \mathbf{2}$ & $116 / \mathbf{3 5}$ \\
\hline
\end{tabular}


Table 2. Perca fluviatilis. Mean, SD, minimum (min.) and maximum (max.) size (total length, TL) of epipelagic (EPF), bathypelagic (BPF) and littoral (LPF) perch fry examined for parasites in 2006 to 2008. EPF and BPF subpopulations were not present in the reservoir during mid-July and mid-August sampling. Sample dates are given as $\mathrm{d} / \mathrm{mo} / \mathrm{yr}$; $\mathrm{p}$-value determined from ANOVA and Tukey's HSD test; ns: not significant

\begin{tabular}{|lcccccccc|}
\hline Date & $\begin{array}{c}\text { Sub- } \\
\text { population }\end{array}$ & $\mathrm{n}$ & \multicolumn{4}{c}{ TL (mm) } & & p-value \\
& Mean SD & Min. Max. & \\
\hline $7 / 6 / 06$ & EPF & 10 & 17 & 1.8 & 14 & 19 & $<0.05$ \\
& BPF & 10 & 19 & 1.2 & 16 & 20 & $<0.05$ \\
& LPF & 10 & 22 & 1.8 & 20 & 26 & $<0.001$ \\
$24 / 5 / 07$ & EPF & 20 & 20 & 0.8 & 18 & 22 & ns \\
& BPF & 20 & 16 & 1.0 & 15 & 18 & $<0.001$ \\
& LPF & 20 & 20 & 1.6 & 17 & 24 & ns \\
$13 / 6 / 07$ & EPF & 20 & 18 & 1.4 & 16 & 21 & $<0.001$ \\
& BPF & 20 & 26 & 2.4 & 20 & 29 & $<0.001$ \\
& LPF & 31 & 33 & 3.4 & 26 & 40 & $<0.001$ \\
$11 / 7 / 07$ & LPF & 19 & 56 & 3.4 & 47 & 61 & \\
$29 / 8 / 07$ & LPF & 20 & 71 & 8.5 & 62 & 95 & \\
& EPF & 15 & 17 & 1.7 & 15 & 21 & $\mathrm{~ns}$ \\
& BPF & 15 & 16 & 1.2 & 14 & 18 & $<0.001$ \\
& LPF & 15 & 18 & 1.9 & 15 & 21 & $\mathrm{~ns}$ \\
\hline
\end{tabular}

and minimum sizes of fish as well as their numbers for each sampling date and each perch fry subpopulation are given in Table 2 .

In total 6 species of endoparasites were found in the EPF, BPF and LPF examined: 4 cestodes, Bothriocephalus claviceps (Goeze, 1782), Glanitaenia osculata (Goeze, 1782), Proteocephalus percae (Müller, 1780) and Triaenophorus nodulosus (Pallas, 1781); 1 nematode, Camallanus lacustris (Zoega, 1776); and 1 acanthocephalan, Acanthocephalus lucii (Müller, 1776). All endohelminths were juvenile or immature. Perch fry were also infected with 2 ectoparasites: Argulus sp. ( 20 and $\sim 5 \%$ prevalence in EPF and LPF, respectively) and the ciliate Trichodina sp. $(\sim 1 \%$ prevalence in EPF and LPF), but these data are not well supported, because ectoparasites may have been lost during collection. No monogeneans were found.

In general, the nematode Camallanus lacustris was the most common parasite (46 specimens in 18 fish), followed by juveniles of the cestode Proteocephalus percae (15 worms corresponding to the stage of plerocercoid, i.e. without segmentation, in 9 fish) (Fig. 1). With the exception of Triaenophorus nodulosus found in the body cavity or already encysted in the liver, all endohelminths were recovered from the intestinal lumen.
A marked difference was found in infection rates in the 3 spatially segregated subpopulations of perch fry (Table 1). Endohelminths were found almost exclusively in LPF, which were heavily infected (overall prevalence of $30 \%$ ). Two species (Camallanus lacustris and Triaenophorus nodulosus) were found in 1 fish each (3\% prevalence) in BPF, whereas EPF were uninfected (Table 1). The 1-way ANOVA demonstrated a difference between the prevalence of infection in 3 subpopulations $(F=9.07, \mathrm{p}<0.05)$. The post-hoc Tukey's HSD test showed significant differences between EPF and LPF ( $p=0.0045)$ and between BPF and LPF $(p=0.0081)$.

Species richness and prevalence of parasites in LPF increased from 20-24 d old perch fry (1 species of parasite per sample, prevalence of 5 to $30 \%$ ) to $106 \mathrm{~d}$ old fry (5 species of parasites, prevalence of $80 \%$ ) (Fig. 1).

\section{DISCUSSION}

In all but one case (24 May 2007) the LPF were always the largest fry in the sample, which corresponds with the previous results of Čech et al. (2005) and Vašek et al. (2006). On 2 sampling dates (7 June 2006 and 13 June 2007), the EPF were significantly smaller than $\mathrm{BPF}$, in contrast to the other 2 sampling dates (24 May 2007 and 29 May 2008) when the situation was completely opposite (Table 2). The subpopulations of EPF and BPF were neither detected using echosounders nor caught using the trawl on the 2 latest sampling dates (11 July and 14 August 2007), which is

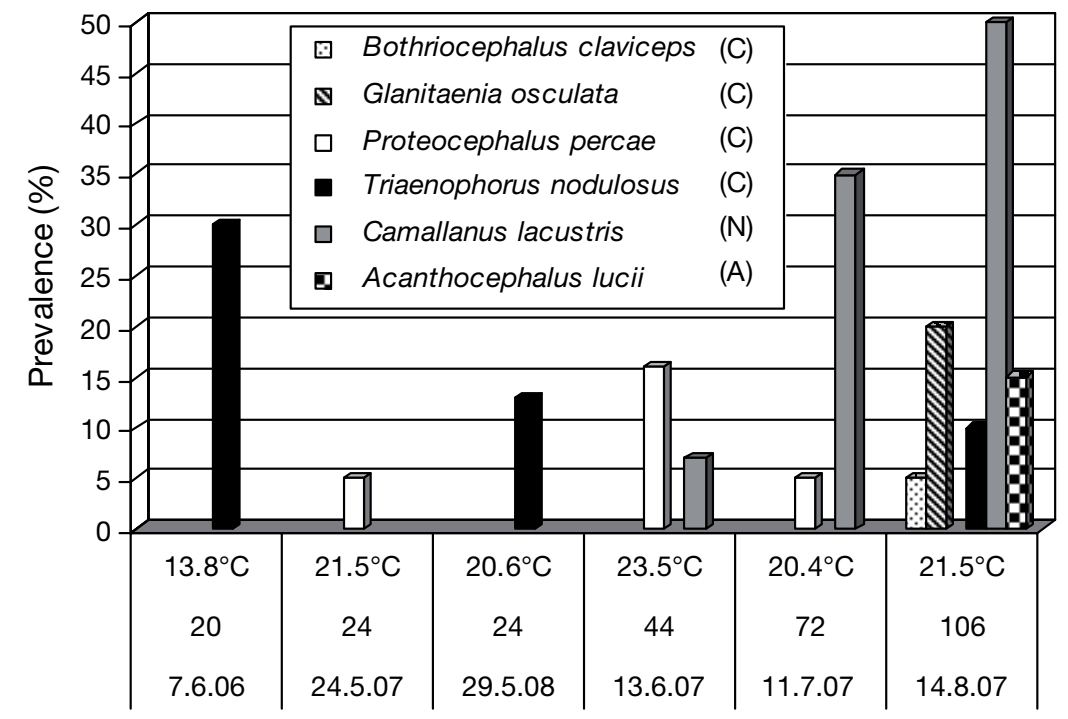

Fig. 1. Perca fluviatilis. Prevalence of endohelminth parasites (A: Acanthocephala; C: Cestoda; N: Nematoda) in the littoral perch fry (LPF) subpopulation with data on water temperature $\left({ }^{\circ} \mathrm{C}\right)$, fry age $(\mathrm{d})$ and sampling date $(\mathrm{d} / \mathrm{mo} / \mathrm{yr})$ 
why they were not included in the parasitological analysis. Most probably a continuous summer shift of perch fry occurred from the pelagic into the littoral habitat of the reservoir (Coles 1981, Wang \& Eckmann 1994, Čech \& Kubečka 2006).

A marked difference in the parasite fauna of perch fry from different subpopulations was found in the present study. These differences may reflect different ecological conditions and availability of intermediate hosts, as well as a different mode of perch feeding in each of the lacustrine zones (see Wierzbicki 1971). Our data indicate that different feeding behaviour occurs early in life and perch from littoral zones are the most heavily infected. A similar observation was reported for adult fish by Wierzbicki (1971).

All but one of the helminth parasites found in perch fry use planktonic copepods as intermediate hosts, which can be correlated with planktonic feeding. The first colonizers of perch fry populations were the tapeworm Triaenophorus nodulosus, which has a 3-host life cycle (definitive hosts are pike Esox lucius L., whereas planktonic fishes such as perch serve as the second intermediate hosts with larvae-plerocercoidsencysted within the liver, Kuperman 1973), and Proteocephalus percae, a specific parasite of perch, rarely found in other percid fishes (Scholz \& Hanzelová 1998). Finding of the acanthocephalan Acanthocephalus lucii in a $106 \mathrm{~d}$ old perch confirms that fry feed upon benthic isopods because this acanthocephalan uses the isopod Asellus aquaticus L. as its intermediate host (Andryuk 1974, Brattey 1988).

The present study also has shown a pronounced spatial structure of parasite communities in perch fry, with considerable difference in the infection rate of littoral versus epipelagic and bathypelagic subpopulations of fish. Similar data are not available for cestodes, but a marked spatiotemporal pattern in communities of larval trematode parasites was recently reported in close (distance of about $50 \mathrm{~m}$ ) littoral and benthic populations of the snail Valvata macrostoma Mörch from Lake Konnevesi in Finland (Faltýnková et al. 2008).

Perch fry in the littoral zone of the Římov Reservoir became infected as early as 20 to $24 \mathrm{~d}$ after hatching by the cestodes Triaenophorus nodulosus and Proteocephalus percae. Bykhovskaya-Pavlovskaya (1940) also reported early infections of perch fry with $P$. percae. Kuperman (1963) experimentally infected perch fry with $T$. nodulosus. He observed that the tapeworm infected perch only in the first months of the host life and noted that this endoparasite does not have a significant effect on the fitness of young perch.

The prevalence of Proteocephalus percae was highest in $44 \mathrm{~d}$ old LPF $(15 \%)$, but the parasite was not found in $106 \mathrm{~d}$ old fry (Fig. 1). The absence of tape- worms at the beginning of autumn may be related to seasonality in the occurrence and maturation of most freshwater fish cestodes in temperate zones (see Chubb 1982, Scholz 1986). Tapeworms, especially proteocephalideans, mature at the end of spring when eggs are laid and specimens of the old generation disappear. Recruitment of the new generation takes place in autumn, usually in October.

Acknowledgements. The authors are grateful to Aneta Kostadinova for critically reading a draft of the manuscript and helpful suggestions, Andrea Bednářová and Martina Borovková from the Institute of Parasitology, Biology Centre of the Academy of Sciences of the Czech Republic, for providing technical assistance and help with dissection of fish, and Mojmír Vašek, Jiří Peterka, Tomáš Jůza, Jaroslava Frouzová, Michal Kratochvíl, Vladislav Draštík, Milan Muška and Zdeněk Prachař from the Institute of Hydrobiology for help with collecting the fish. This study was partially supported by the Grant Agency of the Czech Republic (project nos. 524/08/0885, 206/06/1371 and 206/09/P266), Grant Agency of the Academy of Sciences of the Czech Republic (project no. KJB600960902), Institute of Parasitology (project nos. Z60220518 and LC522) and the Faculty of Science, University of South Bohemia (MSM 6007665801).

\section{LITERATURE CITED}

Andryuk LV (1974) The infection rate of fish with acanthocephalans in the upper reaches of the Dnepr. Byull Vses Inst Gelmintol im KI Skryab 13:5-8 (in Russian)

Bauer ON (1987) Guide for identification of parasites of freshwater fish, Vol 3. Akademiya Nauk SSSR, Leningrad (in Russian)

Brattey J (1988) Life history and population biology of adult Acanthocephalus lucii (Acanthocephala: Echinorhynchidae). J Parasitol 74:72-80

Bykhovskaya-Pavlovskaya IE (1940) Effect of age on changes in the parasite fauna of perch. Parazitol Sb 8:99-130 (in Russian)

Campana SE (1992) Measurement and interpretation of the microstructure of fish otoliths. In: Stevenson DK, Campana SE (eds) Otolith microstructure, examination and analysis. Can Spec Publ Fish Aquat Sci 117:59-71

> Carney JP, Dick TA (1999) Enteric helminths of perch (Perca fluviatilis L.) and yellow perch (Perca flavescens Mitchill): stochastic or predictable assemblages? J Parasitol 85: 785-795

Čech M, Kubečka J (2006) Ontogenetic changes in the bathypelagic distribution of European perch fry Perca fluviatilis monitored by hydroacoustic methods. Biologia 61:211-219

Čech M, Kratochvíl M, Kubečka J, Draštík V, Matěna J (2005) Diel vertical migrations of bathypelagic perch fry. J Fish Biol 66:685-702

Čech M, Kubečka J, Frouzová J, Draštík V, Kratochvíl M, Matěna J, Hejzlar J (2007a) Distribution of the bathypelagic perch fry layer along the longitudinal profile of two large canyon-shaped reservoirs. J Fish Biol 70: $141-154$

> Čech M, Kubečka J, Frouzová J, Draštík V, Kratochvíl M, Jarošík J (2007b) Impact of flood on distribution of bathypelagic perch fry layer along the longitudinal profile of large canyon-shaped reservoir. J Fish Biol 70:1109-1119 
Chubb JC (1982) Seasonal occurrence of helminths in freshwater fishes, part IV: adult Cestoda, Nematoda, and Acanthocephala. Adv Parasitol 20:1-292

Coles TF (1981) The distribution of perch, Perca fluviatilis L. throughout their first year of life in Llyn Tegid, North Wales. J Fish Biol 18:15-30

Ergens R, Lom J (1970) Causative agents of parasitic diseases of fish. ČSAV, Praha (in Czech)

Faltýnková A, Valtonen ET, Karvonen A (2008) Spatial and temporal structure of the trematode component community in Valvata macrostoma (Gastropoda, Prosobranchia). Parasitology 135:1691-1699

Gliwicz ZM, Jachner A (1992) Diel migrations of juvenile fish: a ghost of predation past or present? Arch Hydrobiol 124: 385-410

Kuperman BI (1963) Infection of young perch by the tapeworm Triaenophorus nodulosus. Int Ver Theor Angew Limnol Verh 18:1697-1704

Kuperman BI (1973) Tapeworms of the genus Triaenophorus, parasites of fish. Experimental Systematics, Ecology. Nauka, Leningrad (in Russian)

MacKenzie K, Williams HH, Williams B, McVicar AH, Siddall $R$ (1995) Parasites as indicators of water quality and the potential use of helminth transmission in marine pollution studies. Adv Parasitol 35:85-144

Marcogliese DJ, Gendron AD, Plante C, Fournier M, Cyr D (2006) Parasites of spottail shiners (Notropis hudsonius) in the St. Lawrence River: effects of municipal effluents and habitats. Can J Zool 84:1461-1482

Moravec F (1994) Parasitic nematodes of freshwater fishes of Europe. Kluwer Academic Publishers, Dordrecht

Editorial responsibility: David Marcogliese, Montreal, Quebec, Canada
Scholz T (1986) Observations on the ecology of five species of intestinal helminths in perch (Perca fluviatilis) from Mácha lake fishpond system, Czechoslovakia. Věstn Česk Spol Zool 50:300-320

Scholz T (1989) Amphilinida and Cestoda, parasites of fish in Czechoslovakia. Acta Sci Nat Brno 23(4):1-56

Scholz T, Hanzelová V (1998) Tapeworms of the genus Proteocephalus Weinland, 1858 (Cestoda: Proteocephalidae), parasites of fishes in Europe. Studie AV ČR, No. 2/98. Academia, Praha

Seppälä O, Karvonen A, Valtonen ET (2005) Manipulation of fish host by eye flukes in relation to cataract formation and parasite infectivity. Anim Behav 70:889-894

Vašek M, Kubečka J, Matěna J, Sed'a J (2006) Distribution and diet of $0+$ fish within a canyon-shaped European reservoir in late summer. Int Rev Hydrobiol 91:178-194

Wang N, Eckmann R (1994) Distribution of perch (Perca fluviatilis L.) during their first year of life in Lake Constance. Hydrobiologia 277:135-143

Wierzbicka J, Wierzbicki K, Piasecku W, Śmietana P (2005) A comparative study on the parasite fauna of perch, Perca fluviatilis L., collected from a freshwater coastal lake, brackish-water Baltic Sea, and the interconnecting canal. Wiad Parazytol 51:295-302

Wierzbicki K (1971) The effect of ecological conditions on the parasite fauna of perch Perca fluviatilis L. in Lake Dargin. Ekol Polska 19:73-86

Williams HH, MacKenzie K, McCarthy AM (1992) Parasites as biological indicators of the population biology, migrations, diet, and phylogenetics of fish. Rev Fish Biol Fish 2: 144-176

Submitted: January 30, 2009; Accepted: May 20, 2009

Proofs received from author(s): July 27, 2009 